\title{
Facial Caricaturing Robot COOPER with Laser Pen and Shrimp Rice Cracker in Hands Exhibited at EXPO2005
}

\author{
Takayuki Fujiwara, Takashi Watanabe, Takuma Funahashi, \\ Katsuya Suzuki and Hiroyasu Koshimizu \\ SIST/School of Information Science and Technology, Chukyo University \\ Japan
}

\section{Introduction}

Facial caricature as a facial image media acts as an interface between the user and the computer. We developed the facial caricaturing robot "COOPER" (Fig. 1) that was exhibited at the Prototype Robot Exhibition of EXPO 2005 [1]. COOPER watches the face of a person seated at the chair, obtains facial images, and analyzes the images to extract 251 feature points to generate his facial line drawings with deformation, and gives a caricature drawn by the laser pen on the shrimp rice cracker to the visitor.

We have been developing a facial caricaturing system PICASSO [2], and we customized this system for the exhibition at the EXPO pavilion. This paper illustrates the outline of the COOPER and the details of the image processing fabricated in it. And we discusses on the COOPER's prospects of the future subjects based on more than 395 facial caricatures obtained at EXPO2005.

Fig. 1. External view of COOPER.

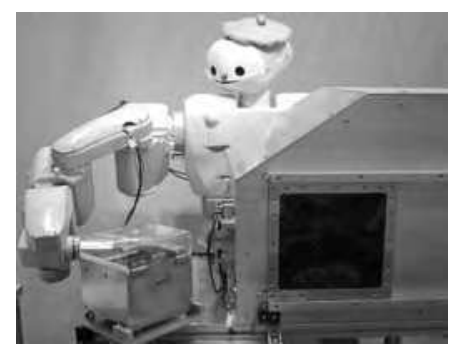

Though there are other systems and products proposed so far that can generate the caricature automatically [3-5], there has been no report on the field test of these systems. Therefore our large trial can also be expected to get facial images covering several races and generations in the grand field test at EXPO. Therefore it would be unique and effective to illustrate what COOPER is and how it performed at EXPO for prospecting the future of computer facial caricaturing.

As a result of 11 days demonstration, COOPER generated 352 caricatures in total and presented a shrimp rice cracker to the respective visitor. This system generated successful output from the standpoint of wide distribution of visitors in generation, race and sexuality at EXPO site. 
In section 2, the outline of COOPER system is summarized, and in section 3, the image processing methods for extracting facial features are introduced. In section 4, the primal experimental results of the exhibition are presented. Some knowledge and future subjects obtained by the considerations of results are shown in sections 5 and 6 .

\section{Configuration of COOPER}

\subsection{Line drawings for facial expression in COOPER}

COOPER draws the facial caricature on the shrimp rice cracker (Fig. 2) with laser pen held in the left hand. This facial data F (defined by Eq. (1)) has 251 feature points and this system expresses the facial caricature with the 2D line drawing by connecting these feature points. COPPER and the original facial caricaturing system PICASSO extract some facial individuality features from the input face and deform these features to generate its caricature as follows: The facial caricature $Q$ is generated by comparing the input face $\mathrm{P}$ with the mean face $\mathrm{S}$, which is defined previously by averaging input faces as shown in Fig. 2 and Eq. (2). This system generates the facial caricature with some exaggeration by specifying its rate $b$ for adjusting the deformation of the caricature to each visitor.

$$
\begin{gathered}
F=\left\{\left(x_{i}, y_{i}\right) \mid i=1,2, \ldots, 251\right\} \\
Q=P+b(P-S)
\end{gathered}
$$

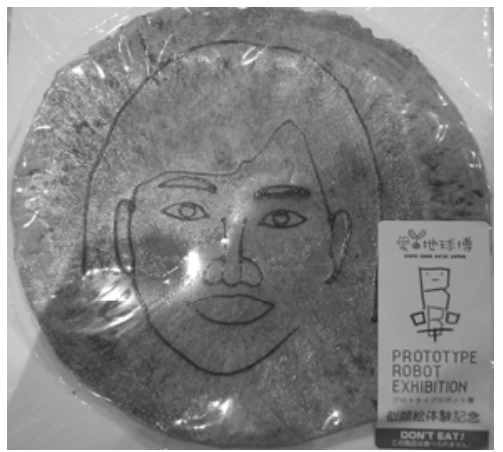

Fig. 2. Caricature on the Shrimp rice cracker.

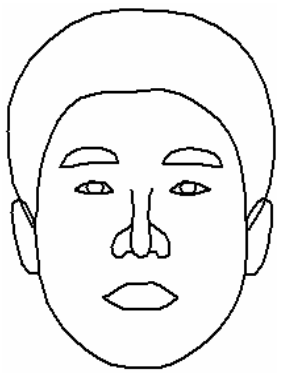

(a) Mean face

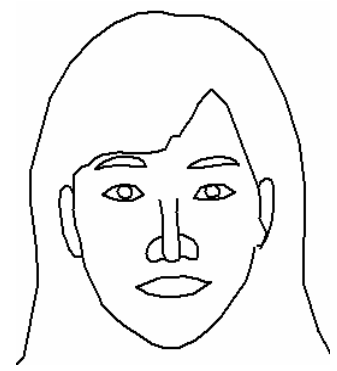

(b) Caricature

Fig. 3. Example of caricature generation. 


\subsection{Hardware modules}

An exterior view of COOPER is shown in Fig. 1. For capturing the facial image, a CCD camera is mounted in the right eye of the head, and a pair of industrial-use robot arm modules are fabricated as the right and left arms. The laser pen mounted at the left arm was connected to the body by the tube type glass fiber not to be fragile due to the arm motion. Laser power was controlled so as to adjust the distance from the pen to the shrimp cracker and surface conditions (temperature, moisture, materials and roughness, etc.) of the cracker. The velocity and the power of the laser pen were controlled smoothly in order to draw the caricature even if the surface of the cracker is rough and distorted.

After many preliminary experiments, we decided the following such conditions that the moisture of the cracker is around $11 \%$ and the surface color of the cracker is brown or black. For the security of the visitors from the laser pen hazard, we fabricated a metal box which covers the laser pen, as shown at the bottom right of Fig. 1.

The industrial-use robot arms were assembled together with the head with cameras, body and legs. Since COOPER has both tilting and rotating mechanisms of the head, we could design the motion of the robot head to be performable like a human caricaturist. We also designed the motion of arms to reduce its loading weight as small as possible and then to realize smoother movement of the arms. We took also the safety conditions into consideration in order to cope with some abnormal operations of the laser pen. System configuration of the robot, control panel and image processing PC is shown in Fig. 4.

We took some auxiliary information of the respective visitor by using touch-sensitive panel as shown in Fig. 5. The contents of this information consist of a kind of facial expression (normal, sad and smiling), sex, age(less than 10, 10's, 20's, 30's, 40's, 50's, more than 60), and his authorization for the usage of his face data for further researches on facial caricaturing.

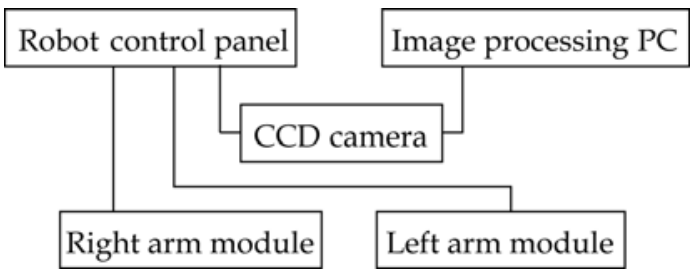

Fig. 4. System Configuration.

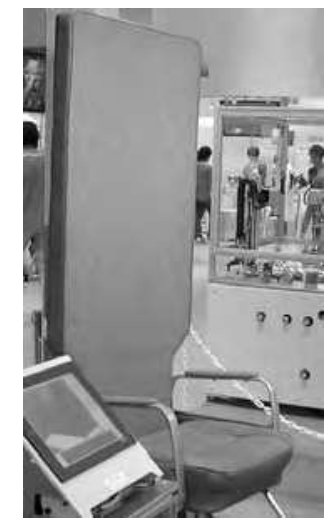

Fig. 5. Touch-sensitive panel and blue backrest chair. 


\subsection{Software modules}

For obtaining the images, the visitors are asked to sit at a chair with the blue backrest, as shown in Fig. 5. This system extracts the facial features from input images, and generates the caricature in the same way as the deformation method of PICASSO system. This system uses a couple of facial images captured by CCD camera with $1 \mathrm{fps}$, because visitors often close the eyes. If this system fails to process the first image, the same procedure is applied again to the second image. Then, COOPER generates the caricature, converts it into the robot control language and finally controls the laser pen.

In this facial image processing, this system first extracts irises and nostrils, and afterward defines the regions of eyes, nose, mouth and ears hierarchically [6]. This system extracts also the hair region and skin color region in addition to the facial parts features. In the final result, this system generates the caricature comprising 251 feature points that are defined originally as the cooper-PICASSO format. This system evaluates simultaneously the quality of the intermediate results including caricature by using "fail-safe modules" as shown precisely in section 3.5. Thus, we have succeeded in designing the robust performance even in the unconditioned circumstance of illumination in EXPO site.

\section{Detailed procedures of facial image processing}

As the preprocessing for extraction of facial features, this system detects skin color region from RGB image. In the preprocessing, blue region of the background is eliminated from the input image. Skin color region is eliminated from input image as shown in Fig. 6 based on the hue discrimination as shown in Fig. 7. This skin color region is defined and used for the successive image processing.

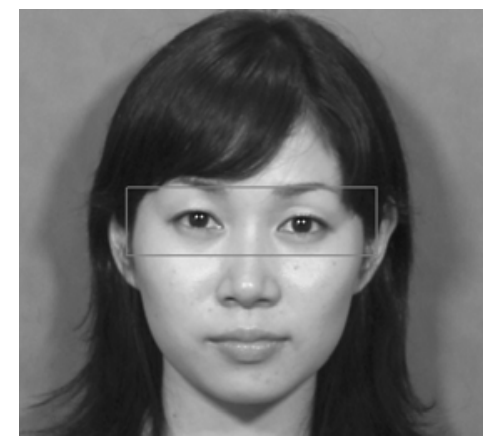

Fig. 6 Input face.

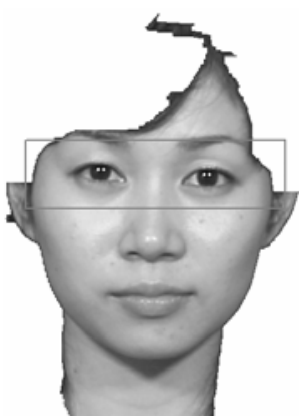

Fig. 7 Skin color region.

\subsection{Irises recognition by Hough transform}

In this system, irises are first extracted by using Hough transform [6] for leading other hierarchical processing modules. Secondly nostrils are extracted in the same way of irises at the nose region. The results of irises and nostrils are shown in Fig. 7.

\subsection{ROI extractions for Facial parts}

The regions of interest (ROI) of eyes, nose, mouth and ears are defined on the basis of the information on irises and nostrils. Fig. 8 shows an example of ROI extraction. 
Fig. 8. Example of facial features extraction.

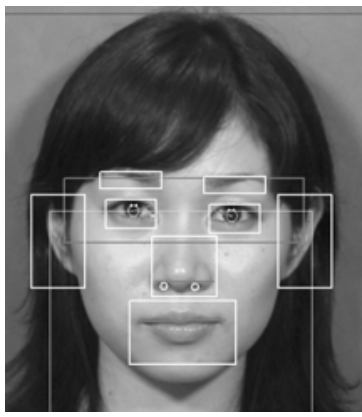

\subsection{Contour extractions of facial parts}

As defined in each facial parts region, outlines of eyes, nose, mouth and ears are detected at the respective ROI of the gray image by using smoothing, contrast improvement, thresholding and thinning procedures. We basically designed that the caricature of COOPER is represented with a set of line drawings. This means that the face of line drawings is less informative than the original image in physical meaning, but that the face of line drawings is more effective than the face image in impression. In this sense, the shape feature of the face contour, hair and jaw is more dominant than the gray image. Moreover the fact that the face of line drawings is easier to realize the correspondence among faces than the face images is one of the technical advantages.

The outline of hair is detected from the binary image by the method of smoothing, contrast improvement and thresholding, as shown in Fig. 9.

The outline of jaw is detected from $\mathrm{R}$ image of RGB color image by using Sobel operator and thresholding, as shown in Fig. 10.

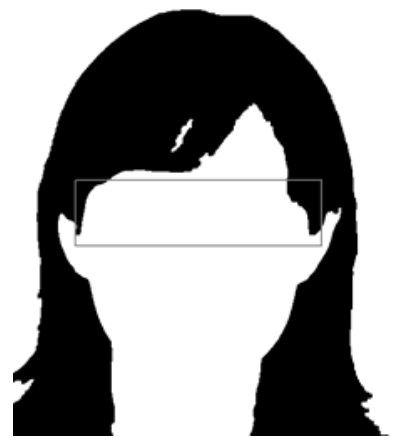

Fig. 9. Hair region.

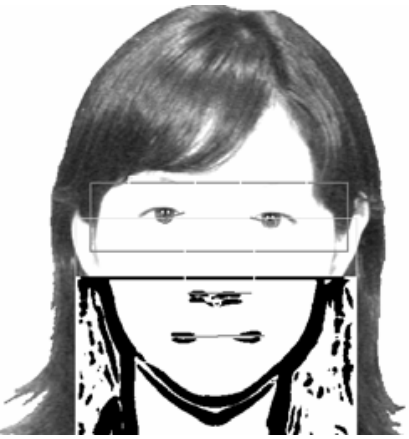

Fig. 10. Pre-processing of jaw extraction.

\subsection{Details in fail-safe module}

At the same time of the extraction of facial parts, this system evaluates how feasible the result is, and modifies the result, if necessary, according to the statistical standard for the positional relationship among facial parts. This fail-safe system evaluates the result by the estimation function preliminarily prepared [7] which was defined by the difference between the result of the input face and mean face. If this system rejects the result, it is replaced by the corresponding facial parts of the mean face and fitted it as the facial parts. 


\section{Demonstrations in EXPO2005}

\subsection{2 facial data}

We demonstrated successfully that COOPER system could be exhibited at the Prototype Robot Exhibition of EXPO 2005, Aichi Japan. COOPER watches the face of a person and generates his facial line drawings with deformation. The details of Prototype Robot Exhibition are as follows:

Name: Prototype robot exhibition, The 2005 World Exposition, Aichi, Japan

Location: The Morizo and Kiccoro Exhibition Center of Nagakute Area

Duration: Jun.9 to Jun.19, 2005 (11 days in total)

Number of visitors:

to EXPO: $1,129,390$

to Prototype robot exhibition: 123,000

The number of caricatures presented: 352

\subsection{Successful cases with famous visitors}

Many famous people visited our site as television coverage. Fig. 11 shows Japanese famous people.

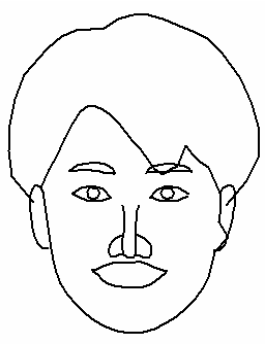

(a) Maoko Kotani.

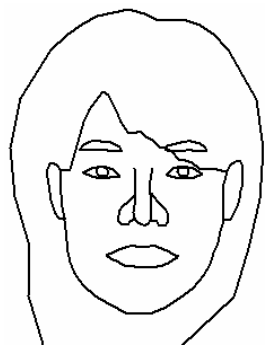

(b) Mana Mikura.

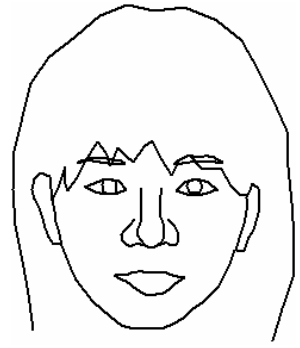

(c) Kana Mikura.

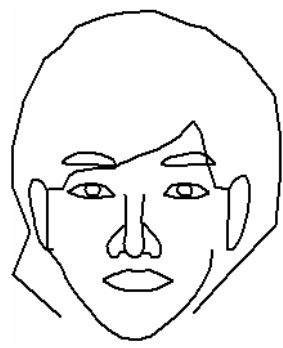

(d) Kumiko Endo.

Fig. 11. Caricatures of Japanese famous people.

\subsection{Un-successful cases}

Investigating the experimental results, it was known that a few un-successful caricatures were generated due to several causes of image processing processes. The detailed statistics of the results will be introduced in subsection 5.1. The examples of the causes of the unsuccessful cases are shown as follows:

(1) Irises recognition

Un-successful caricatures were strongly affected by the failure in irises recognition due to the un-expected blinking. We, therefore, have to develop such new module that could detect the blinking automatically.

(2) ROI extraction

Facial parts of ROI couldn't be occasionally extracted at the proper location. We must try to improve the method for extracting ROI involving the major part of the respective facial parts at least.

(3) Contour extraction of facial parts

The contour of facial parts couldn't be frequently detected at the proper position due to the existence of noise. We must try to improve the method for robust detection of the facial parts contour. 


\section{Considerations and coming subjects}

\subsection{Statistics of success rate for facial parts recognition}

We evaluated statistically the experimental results based on the subjective visual investigations of more than 10 testees visual judgments. The case of examples of unsuccessful caricature is less than 10 percent. Even if un-successful caricature was generated, this system was able to modify the caricature to be acceptable to the image processing by using fail-safe module. There is a small difference between the successful caricature and the extraction rate of facial feature points as shown in Table 1. The row B of Table 1 is the number of successes. The row $\mathrm{C}$ and $\mathrm{D}$ of Table 1 are the number of un-successful extraction of facial parts and successful extraction at the 2nd frame. Our system worked with stable performance because this system first detects irises and nostrils and afterward extracts other facial parts hierarchically. The total number of these examples is 77. Thus we succeeded in designing this system to be absolutely fail-safe. Finally the number of unsuccessful caricatures became 22, and our system provided the smoother operation throughout the whole exhibition. These un-successful cases were caused by the irregular direction of face and irregular condition of eyes under the illumination.

\begin{tabular}{|c|c|c|c|c|c|c|c|c|c|c|c|c|}
\hline date & $6 / 9$ & $6 / 10$ & $6 / 11$ & $6 / 12$ & $6 / 13$ & $6 / 14$ & $6 / 15$ & $6 / 16$ & $6 / 17$ & $6 / 18$ & $6 / 19$ & total \\
\hline A & 46 & 33 & 30 & 29 & 29 & 31 & 32 & 33 & 35 & 34 & 20 & 352 \\
\hline B & 34 & 25 & 22 & 21 & 17 & 19 & 26 & 30 & 17 & 28 & 14 & 253 \\
\hline C & 4 & 0 & 2 & 0 & 2 & 1 & 1 & 1 & 1 & 0 & 1 & 13 \\
\hline D & 4 & 8 & 4 & 8 & 8 & 8 & 4 & 0 & 14 & 3 & 3 & 64 \\
\hline E & 8 & 8 & 6 & 8 & 10 & 9 & 5 & 1 & 15 & 3 & 4 & 77 \\
\hline F & 3 & 0 & 1 & 0 & 2 & 3 & 1 & 2 & 2 & 3 & 2 & 19 \\
\hline G & 1 & 0 & 1 & 0 & 0 & 0 & 0 & 0 & 1 & 0 & 0 & 3 \\
\hline
\end{tabular}

Table 1 Statistics of caricatures

(A: Number of generated caricatures, B: Number of successful generation of caricature, C: Number of unsuccessful extraction of irises and nostrils and successful extraction of 2nd frame, D: Number of unsuccessful extraction of other facial parts and successful extraction of 2nd frame, E: Number of generation of fail-safe system, F: Number of unsuccessful generation of operators' check, G: Number of fatal failure)

\subsection{Coming subjects and prospects of COOPER}

Although COOPER demonstration in EXPO was almost absolutely successful, the following coming subjects were extracted based on the detailed investigations of the experimental results.

(1) Head tracking

As shown in Fig. 12, COOPER is likely to fail to capture the adequate facial images since the visitor such as a boy often moves in front of the camera. In order to cope with this unexpected situation, COOPER must be enforced to be able to track the head automatically.
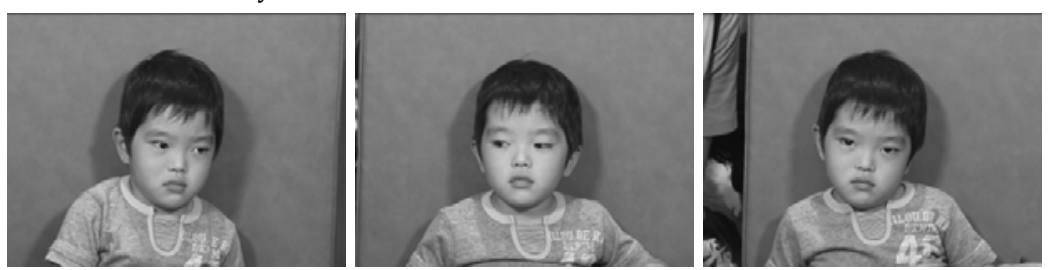

Fig. 12. Example of a series of images of moving child in front of camera. 
To prospect the future of this subject, let us show some preliminary experiments of head tracking for acquiring the facial images with sufficient size for the facial parts recognition. The outline of the system is shown as follows:

Fig. 13 shows the configuration of the system composed by a pair of PTZ and fixed CCD cameras connected to the host PC system. The fixed CCD camera is to track the head of a person who is performing freely in front of it, and the position and the size of the extracted head are transmitted to PTZ camera to control the Pan, Tilt and Zoom parameters. CCD camera can watch and catch a person's face and PTZ camera captures his facial image with sufficient resolution for the image processing in a video rate.

Consequently, an area where a person can freely perform will be enlarged as shown at the dotted region in Fig. 13.

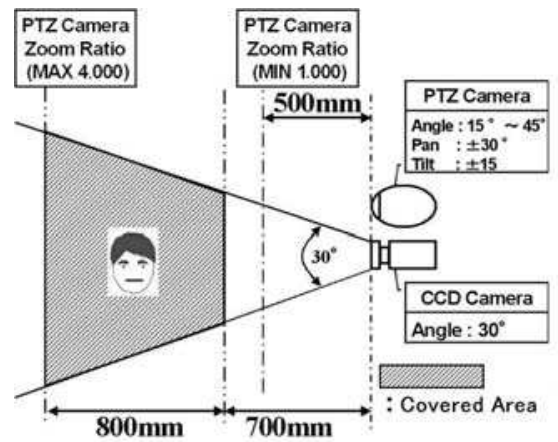

Fig. 13. CCD and PTZ cameras for head tracking.

By transmitting the location of the head together with the size $\mathrm{L}$ of the extracted face region to PTZ camera, the vertical, horizontal and depth movements of the head are estimated simultaneously and PTZ camera is controlled to stabilize the proper size of the facial image. The zoom parameter $\mathrm{Z}$ is determined inversely proportional to L by eq.(3).

$$
Z=\frac{Z \max }{\operatorname{Lmax}-\operatorname{Lmin}} \times(\operatorname{Lmax}-L)
$$

Here, Lmax and Lmin are the maximum and minimum values of this PTZ camera zoom specification, respectively.

(2) Eye contact in facial caricature

As the facial caricature is a new kind of facial interface media in communication, it is essential even in the caricature generation whether the eye gaze expression could be provided or not.

In order to solve this subject, we have been conducted a preliminary research for generating eye-contacted facial image based on the iris recognition. Fig. 14 shows a set of examples.
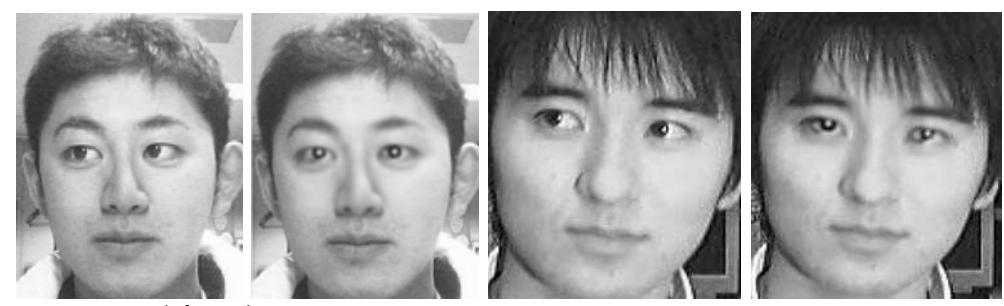

Fig. 14. Eye-contacted facial images. 
(3) Motion in caricature

Facial caricature could be extended in motion such as smiling, because we have the individual facial feature of the motion in emotional expression.

In order to take this subject into consideration, we have been studied a preliminary discussion on the motion exaggeration. Fig. 15 shows an example of motion caricature.
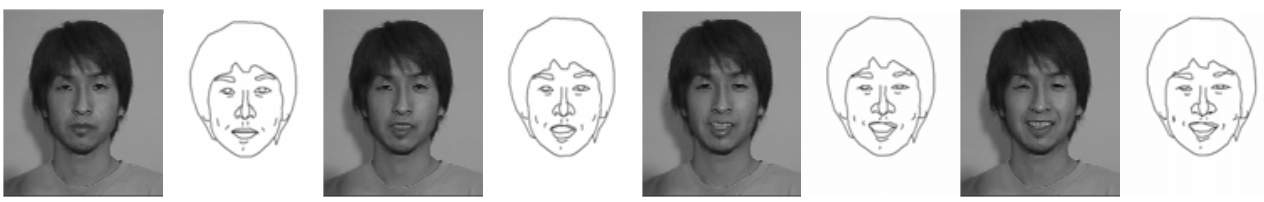

Fig. 15. Facial expression in motion caricature.

\section{Conclusion}

This paper describes the outline of development of caricaturing robot and the knowledge acquired at the presentation in EXPO 2005. It was known that our system COOPER could perform successfully at EXPO as the grand field test site. As a result, it was fruitful and noteworthy for us that we could collect a large number of facial images from younger and middle ages of both male and female.

However, we should investigate more the intensive evaluation of the caricatures. We try to improve the method for the analytical verification of the detailed shape features of facial parts. And COOPER is likely to suffer sometimes from the fatal degradations in the feature extraction caused by an irregular condition of the facial direction and illumination. We must develop robust method for decrease these problems.

As the future works, we are going to improve these subjects and to exhibit COOPER at other events.

\section{Acknowledgements}

This paper was partially supported by the New Energy and Industrial Technology Development Organization, Project for the Practical Application of Next-Generation Robots (the area of prototype development support).

\section{References}

[1] Robot Project: Prototype Robot Exhibition: http://www.expo2005.or.jp/jp/C0/C3/C3.8/C3.8.2/C3.8.2.6

[2] Koshimizu, H. (1997) Computer Facial Caricaturing, Trans. The Institute of Image Information and Television Engineers, Vol.51, No.8, pp. 1140-1146.

[3] Caricaturing robot, EXPO'85, Matsushita pavilion: http://www.mid.co.jp/mid/shirahama/nigaoe.html

[4] Takigawa, E. Kishiba, H. and Kawade, M. (2002) @face Automatic Gender and Age Estimation with Face, Proc. of the Conf. on Japanese Academy of Facial Studies 2002, p171, 1346-8081

[5] Teranishi, K. Kotani, N. and Shinya, M. (2000) Chara-Face: Aportrait Caricaturing System, Proc. of General Conf. on IEICE, A-14-5 
[6] Funahashi, T. Fujiwara, T. Tominaga, M. and Koshimizu, H. (2005) Hierarchical Face and Facial Parts Tracking and Some Applications, Proc. of 7th International Conference on Quality Control by Artificial Vision, 4-9902515-0-4, Nagoya Congress Center, May 2005, pp.305-310, The committee of QCAV, Nagoya Japan

[7] Fujiwara, T. Ushiki, R. Taga, M. and Koshimizu, H. (2002) A Method of Facial Attribute Classification based on Statistic Analysis of the Relationship among Facial Parts, Journal of Japanese Academy of Facial Studies, Vol.2 No.1, pp.25-38, 1346-8081 


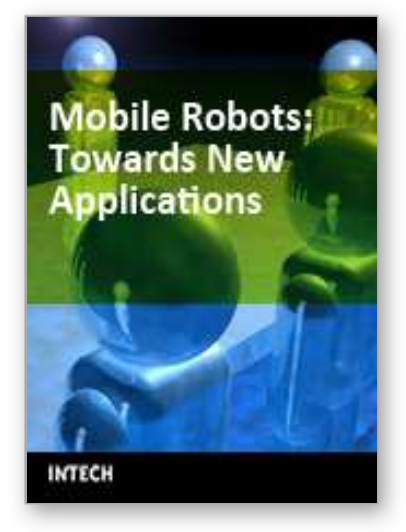

\author{
Mobile Robots: towards New Applications \\ Edited by Aleksandar Lazinica
}

ISBN 978-3-86611-314-5

Hard cover, 600 pages

Publisher I-Tech Education and Publishing

Published online 01, December, 2006

Published in print edition December, 2006

The range of potential applications for mobile robots is enormous. It includes agricultural robotics applications, routine material transport in factories, warehouses, office buildings and hospitals, indoor and outdoor security patrols, inventory verification, hazardous material handling, hazardous site cleanup, underwater applications, and numerous military applications. This book is the result of inspirations and contributions from many researchers worldwide. It presents a collection of wide range research results of robotics scientific community. Various aspects of current research in new robotics research areas and disciplines are explored and discussed. It is divided in three main parts covering different research areas: Humanoid Robots, Human-Robot Interaction, and Special Applications. We hope that you will find a lot of useful information in this book, which will help you in performing your research or fire your interests to start performing research in some of the cutting edge research fields mentioned in the book.

\title{
How to reference
}

In order to correctly reference this scholarly work, feel free to copy and paste the following:

Takayuki Fujiwara, Takashi Watanabe and Takuma Funahashi (2006). Facial Caricaturing Robot COOPER with Laser Pen and Shrimp Rice Cracker in Hands Exhibited at EXPO2005, Mobile Robots: towards New Applications, Aleksandar Lazinica (Ed.), ISBN: 978-3-86611-314-5, InTech, Available from:

http://www.intechopen.com/books/mobile_robots_towards_new_applications/facial_caricaturing_robot_cooper _with_laser_pen_and_shrimp_rice_cracker_in_hands_exhibited_at_expo20

\section{INTECH}

open science | open minds

\section{InTech Europe}

University Campus STeP Ri

Slavka Krautzeka 83/A

51000 Rijeka, Croatia

Phone: +385 (51) 770447

Fax: +385 (51) 686166

www.intechopen.com

\section{InTech China}

Unit 405, Office Block, Hotel Equatorial Shanghai

No.65, Yan An Road (West), Shanghai, 200040, China

中国上海市延安西路65号上海国际贵都大饭店办公楼 405 单元

Phone: +86-21-62489820

Fax: $+86-21-62489821$ 
(C) 2006 The Author(s). Licensee IntechOpen. This chapter is distributed under the terms of the Creative Commons Attribution-NonCommercialShareAlike-3.0 License, which permits use, distribution and reproduction for non-commercial purposes, provided the original is properly cited and derivative works building on this content are distributed under the same license. 